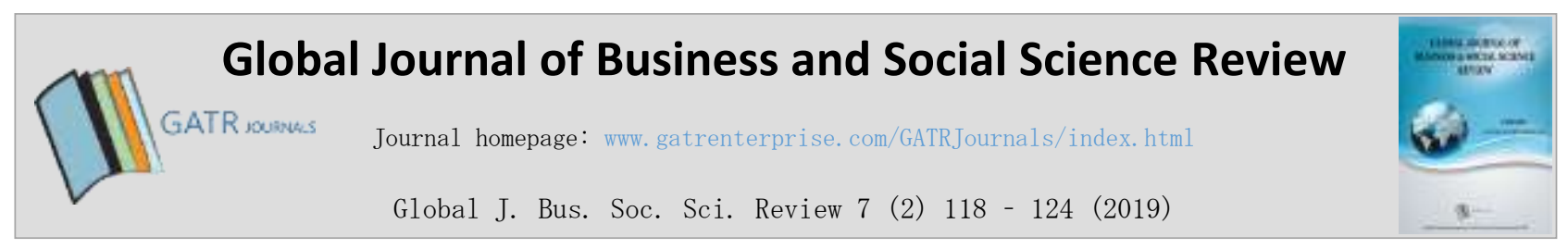

\title{
Challenges Faced by Malaysian Parents in Caregiving of a Child with Disabilities
}

\author{
Norliza Saiful Bahry, ${ }^{1}$ Azmi Mat, ${ }^{2}$ Nur Liana Kori, ${ }^{3}$ Ainunnazlee Mohd Ali, ${ }^{4}$ Zarina Abdul \\ Munir, ${ }^{5}$ Mohammad Zaim Mohd Salleh ${ }^{6}$
}

Faculty Business and Management, Universiti Teknologi MARA, 42300 Puncak Alam, Selangor, Malaysia.

\begin{abstract}
Objective - Caregiving of a child with special needs can increase the cost of raising the child and parent's stress. These two issues are commonly experienced by a parent who care for their special needs child themselves and the thought of challenges are different based on the disability of the child.

Methodology/Technique - The challenges of raising a child with disability make it necessary for parents to work harder to to meet the cost of treatment. Meanwhile, levels of stress among those parents are understandably increased.

Finding - Parents caring for a child with disability need to place greater emphasis on achieving a balance between their work, caring for their child and stress. Further, this paper includes a discussion on the cost of raising a disabled child and the increased levels of stress experienced by these parents.

Novelty - The findings of this paper contribute to conceptual model on the challenges faced by Malaysian parents in caregiving for a child with special needs.

Type of Paper: Review

Keywords: Caregiving Child; Disabilities Child; Parents Stress; Cost of Raising.

Reference to this paper should be made as follows: Bahry, N.S.; Mat, A.; Kori, N. L.; Ali, A. M.; Munir, Z. A.; Salleh, M. Z. M. (2019). Challenges Faced by Malaysian Parents in Caregiving of a Child with Disabilities, Global J. Bus. Soc. Sci. Review 7 (2): 118 - 124. https://doi.org/10.35609/gjbssr.2019.7.2(2)
\end{abstract}

JEL Classification: I10, I14, I19.

\section{Introduction}

Children with special needs are defined by the Salamanca Statement in 1994 as "children or youth whose needs arise from disabilities or learning difficulties". According to the Law of Malaysia (2008), children with disabilities, commonly known as anak kurang upaya (OKU) or anak istimewa in a Malaysian context, refers to any child (under the age of 18) with long-term physical, mental, intellectual and (or) sensory impairment that, upon interaction with various barriers, can prevent them from participating fully and effectively in society (Siti Nor Ismalina et. al. 2016).

\footnotetext{
${ }^{*}$ Paper Info: Revised: March 9, 2019

Accepted: June 22, 2019

* Corresponding author: Norliza Saiful Bahry

E-mail: norliza_sb@yahoo.com

Affiliation: Faculty Business and Management, Universiti Teknologi MARA (UiTM), Malaysia.
} 
More specifically, the types of disabilities are divided into seven categories, including: hearing, visual, physical, learning, mental, speech and multiple disabilities, as extracted from UNICEF Malaysia (2014) and depicted in Table 1.

Table 1: Categories of Disabilities

\begin{tabular}{|c|c|c|}
\hline No. & Category & Explanation \\
\hline 1. & Hearing & $\begin{array}{l}\text { Unable to hear clearly in both ears without the use of a hearing aid or unable to } \\
\text { hear at all even with the use of a hearing aid. }\end{array}$ \\
\hline 2. & Vision & $\begin{array}{l}\text { Blind in both eyes or blind in one eye or limited vision in both eyes or any } \\
\text { other permanent visual impairment. }\end{array}$ \\
\hline 3. & Speech & $\begin{array}{l}\text { An inability to speak that impairs proper communication and cannot be } \\
\text { understood by those interact with the person. }\end{array}$ \\
\hline 4. & Physical & $\begin{array}{l}\text { Permanent inability of parts of the body whether caused by loss or absence or } \\
\text { the inability of any part of the body that can affect their functions in fully } \\
\text { carrying out basic activities. (Example: Limb defects, spinal cord injury, stroke, } \\
\text { traumatic brain injury, Dwarfism, Cerebral Palsy) }\end{array}$ \\
\hline 5. & Learning Difficulties & $\begin{array}{l}\text { Intellectual capabilities that do not conform with biological age. (Example: } \\
\text { Late Global Development, Down Syndrome and Intellectual Disabilities) } \\
\text { This category also includes conditions that affect the learning ability of an } \\
\text { individual such as Autism, Attention Deficit Hyperactivity Disorder (ADHD) } \\
\text { and specific learning difficulties such as Dyslexia, Dyscalculia and Dysgraphia. }\end{array}$ \\
\hline 6. & Mental & $\begin{array}{l}\text { Severe mental illness that causes an inability to function in person whether } \\
\text { partly or fully in matters related to him/herself or his/her relationship within the } \\
\text { community. } \\
\text { Among the types of mental illness are serious and chronic Organic Mental } \\
\text { Disorder, Schizophrenia, Paranoia, Mood Disorder (depression, bipolar) and } \\
\text { other Psychotic Disorders (Schizoaffective Disorder and Persistent Delusional } \\
\text { Disorder) }\end{array}$ \\
\hline 7. & $\begin{array}{l}\text { Various (Multiple } \\
\text { Disabilities) }\end{array}$ & $\begin{array}{l}\text { Having more than one type of disability and in general is not appropriate to be } \\
\text { classified in category I to VI. }\end{array}$ \\
\hline
\end{tabular}

(Sources: https://www.unicef.org/malaysia/UNICEF-Children_with_Disability_in_Malaysia_2014_lowres.pdf)

According to the Department of Social Welfare (2015), the number of children with disability in Malaysia between the ages of 0 and 18 years old is 105,174. However, in 2016, there was an 8.5 percent increase in the number of disabled children in Malaysia and the statistics show that children with disabilities account for 28 percent of the disabled population in Malaysia (Department of Social Welfare, 2016). Furthermore, approximately 10 - 16 percent of all children have disabilities; these figures vary according to the data source, definition used, and community surveyed (Ammar, 2008). Statistics from 2016 produced by the Department of Social Welfare Malaysia reported the highest registered category of disability as learning disability with the lowest being mental disability (Department of Social Welfare, 2016). Based on research by Tan and Yadav (2008), delayed speech is the most common disability among the entire age group while cerebral palsy is the lease common. In addition, according to Amar (2008), 10 to 16 percent of pre-school children aged between 5 to 6 years old have an intellectual disability, Attention Deficit Hyperactivity Disorder, Pervasive Developmental Disorders (Autism, ASD, Asperger), Learning Disability (e.g. Dyslexia, Cerebral Palsy, hearing impairment, visual impairment) and/or visual disorders (squint, amblyopia, refractive error). Furthermore, in a recent study by Kamaralzaman, Toran, Mohamed and Abdulla (2018), it was 
reported that approximately 47,000 people in Malaysia are autistic and it is estimated that one out of every 600 children is born with autism. However, the actual data is still being gathered to determine the total number of the children with disability in Malaysia (UNICEF, 2017).

Family caregivers play an important role in the wellbeing of disabled children. A care giver is defined as "the parent (either mother or father) or other family members (grandmother or grandfather, siblings, aunt or uncle and adoptive parent) of the disabled child who are responsible for parenting or caring for the disabled child" (Siti Nor Ismalina, et. al, 2016). According to Juhásová (2015), a child with disabilities represents a heavy psychological, physical, social and economic burden for a family. Parenting a child with disabilities goes beyond 'ordinary' parenting, and the parents must cope with many changing demands related to their child's specific needs (Siti Nor Ismalina, et. al, 2016). When caring for a disabled child, it becomes increasingly difficult to balance their working life and their attention to their child. A healthy family development will affect the development of a child with disabilities (Juhásová, 2015). The most important part of caring for child with disabilities is undertaken by the family and their local community. Hence, this study focuses on the issues and challenges in caring for a child with disabilities. In addition, this study identifies strategies to minimize issues and maximize the facilities for caring for a disabled child. Moreover, the aim of this research is to compare the quality of life between families with disabled children and families without disabled children in Malaysia.

\section{Challenges of Caregiving for a Disabled Child}

Most of the literature relating to caring for a child with special needs highlight several ways to reduce the caregiving burden and increase the caregiver's quality of life. Three major issues of caregiving disabled children are highlighted in this study, including: the cost of raising disabled children, parenting stress and additional time allocation. Understanding the issues and challenges these parents face can be understood through conversation of resources theory. According to Hobfoll et. al. (2011), The Conservation of Resource Theory is a reliable basis for understanding the process involved with experiencing, coping with, and overcoming chronic and traumatic stress. According to that theory, a certain level of stress is incurred when an individual's resources are threatened, depleted, or when investment(s) in new resources do not adequately increase (Joyner \& Leake, 2018; Hobfoll et. al., 2011). Resources are defined as anything that the person values, specifically objects (e.g., house, car, telephone), states (e.g., optimism, hope, knowledge), and conditions (e.g., stable employment, good financial, good health, work-life balance). Through the lense of the Conversation of Resource Theory, raising a child with challenging disorders is likely to strain one's cognitive and physical resources which may lead to different levels of stress (Hobfoll, 1989). In addition, Boundary Theory provides a good understanding for managing one's work and family roles. Boundary Theory examines the mechanisms people enact to create, maintain, and change boundaries in order to classify and simplify their world (Ashforth, Kreiner \& Fugate, 2000). When caring for a child with disabilities, it is likely that the caregiver will require a high level of integration between their work and family roles in order to meet their child's needs.

\section{Cost of Raising Disable Child}

In a recent UNICEF (2016) report, it was stated that financial barriers are one of the major burdens in caregiving for a child with disabilities (UNICEF, 2016). Those barriers include transport to services, medical bills, nutritional supplements, diapers, and assistive devices. In addition, they received limited disability allowances, which increases the financial strain. Nowadays, the cost of raising disabled children is very expensive and burdensome for parents. Items such as food, special equipment or devices uses for the child have increased in cost over time. A survey conducted in Kelantan by Surianti, Raishan, Azizah and Mohd (2017) reports that living with disabilities generates extra costs and a majority of the mothers surveyed were not able to afford the resources they believe are essential for their disabled children. According to Suriati, 
Zainiyah, Lye, and Norlijah (2011), two-thirds of caregivers earn less than RM2000 which may further compound the need for financial support. The findings of that study show that most parents do not have financial stability and need to earn more money to meet the costs involved with caregiving for disabled children. This is also the case in other countries; Newacheck and McManus (1998) have found that a parent spends almost twice as much when caring for a disabled child, including costs of medical expenses. Moreover, Loprest and Davidoff (2004) examine the impact of having a child with special health care needs (CSHCN) on low-income parents' employment and reveal that parents spends a significant amount on medical and treatment costs that are, for the most part, unaffordable. Those parents have additional expenses, which require them to work harder to increase their financial support. In another study, 45 percent of families reported incurring extra expenses for these children (Meyers, Brady, Seto, 2006). The need for increased incomes would tend to increase the likelihood of work.

One study related to the economic burden of families with Autism Spectrum Disorders (ASD) children, comprehensively discussed the costs incurred and burden of raising those children children in Malaysia. As shown in Table 2, the costs can be classified into direct and development costs. Direct costs refers to medical direct costs and non-medical direct costs. Direct medical costs refers to the purchase of medical, diagnostic test, surgery ward, entrance fees, treatment, medical and therapy fees. Non-medical direct costs, however, includes transportation and accommodation costs related to the use of medical services. Amar (2018) also further states that the cost of raising disabled children includes pediatric treatment, physiotherapy and occupational therapists, speech or language therapists and child psychology. All of these treatments are important to ensure the positive improvement of their child. Meanwhile, development costs refer to domestic helpers, nurseries, special education, special diets, daily necessities and insurance. These cost fall in the range of RM 25,763 to RM 37,905.

In Malaysia, the learning options for students with special needs fall within three broad categories of special needs: visual impairment, hearing impairments and learning disabilities in special schools and integration programs in mainstream schools (Norshidah \& Manisah, 2010). Despite the positive developments in providing education for children with disabilities, Muhamad and Alfa (2016) report that there remain an abundance of challenges that need to be addressed and resolved by different stakeholders, namely, the Ministry of Education, teachers and school management. The authors also explain that in Malaysia, there remain issues in unsupervised and unstructured early intervention programs, poor infrastructure, and technological accessibility, financial constraints, low level of readiness among special and general educators and individual self-conflict. Due to the issues in public special needs school, some parents choose to send their children to private special education where the fees can range from RM1000 to RM4500 per month. Although those costs are a burden on those families, they struggle to fulfil the needs in order to ensure that their children maintain healthy, active and continuous development (Kamaralzaman, Toran, Mohamed \& Abdulla, 2018). Due to rising costs, most families require both the husband and wife to work in order to earn extra financial support.

\section{Parenting Stress}

Caregiving of disabled children is challenging for the parents. Olsson and Hwang (2001) report that parents of children with disabilities are likely to experience a higher burden compared to parents of children that do not have disabilities. Some of the challenging aspects of caring for these children include excessive caring burden, less quality time with family members, handling sibling problems, education and future concerns, as well as financial difficulties (Shirley, Amily, Zulhabari \& Norashikin, 2017). Furthermore, they need to spend extra time to assist in feeding, dressing and walking children with physical disabilities, whilst some children with learning disabilities may have difficulties in understanding and following instructions (Suriati et. al., 2011).

The physical and mental stress associated with raising children with disabilities could be multifold (Ganjiwale, Ganjiwale, Sharma \& Mishra, 2016). Studies have shown that parental stress is related to the 
psychological well-being and QoL of caregivers (Siti Nor Ismalina, et. al., 2016; Cramm \& Nieboer, 2011). Parents with disabled children experience more stress as they must assist the child to do things such as eating, moving, clothing, and personal hygiene. Coping with all of these stresses is one of the challenges for these parent. According to Allik, Larson and Smedje (2006), many parents have experienced intense feelings of anger, guilt, depression or anxiety most of the time.

Immediate attention needs to be given to these parents to avoid burnout and other mental health issues (Pushpalatha \& Shivakumara, 2016). A recent study found that more than half of the respondents with autistic children experienced a moderate burden and nearly half of them had mild to moderate stress (Nagaraju \& Wilson, 2013). Visilopoulou and Nisbet (2016) also state that parents of children with ASD have higher rates of stress, depression, and anxiety as compared to parents of typically developing children and children with other developmental disabilities. It can be concluded that, in addition to the financial stress and physical stress of caregiving for disabled children, the prevalence of caregiver stress is also caused by the difficulties of adapting to the several roles parents are required to fulfil.

\section{Time Allocation}

Maintaining a full-time job and caring for a child with special needs is undoubtedly difficult (Shirley et. al., 2017). Those parents must find balance between their work and the care of their children. Time requirements may be regular or highly unpredictable (Loprest \& Davidoff, 2004). Due to the many conflicting requirements of both full-time work and caregiving for their child, those parents often find it difficult to balance their schedule and/or take leave from their paid employment (Shirley, et. al., 2017). Therapy and hospital appointments for their children usually take a long time and require a parent to spend a lot of time away from their job. In Malaysia, not all of the local or even private hospitals provide sufficient specialized services for disabled children. This is due to the limited supply of assistive devices and limited expertise of therapists, psychiatrists, doctors and medical officers. Shirley et. al., (2017) states that the inability to allocate adequate time to either of their roles may be another source of stress for those parents.

\section{Proposed Research Methodology}

The aim of this research is to compare the quality of life between families with disabled children and families without disabled children in Malaysia. The quality of life is compared from the point of view of parents based on the physical, psychological, social and environmental aspects. The first group of respondents consists of parents who care for a disabled child under the age of 18. The second group, consisting of a family without a disabled child, will be used as the control to compare the quality of life between the two types of families. This study is conducted using convenient sampling techniques and quantitative studies.

A self-administered questionnaire will be given to the parents with disabled children and parents without a disabled child. In the first section of the questionnaire, the caregiver and child's socio-demographic characteristics will be examined to determine if there are any subgroup differences. The second section of the questionnaire will be adapted from a standardized questionnaire of the World Health Organization for the assessment of quality of life WHOQOL-BREF which was originally created in 1995 and has been validated by several studies in specific subgroups of the population (Kruithof, et. al., 2018).

\section{Conclusions}

In conclusion, the challenges of caregiving differ depending upon the type of disability of the child and the socio-demographic background of the family. In general, however, most of the parenting burden stems from difficulties with time allocation, treatment and equipment costs as well as the balance between paid employment and caring responsibilities. The implication of this study is to identify recommendations for the

Global J. Bus. Soc. Sci. Review 7 (2) $118-124$ (2019) 
government to develop better policies and facilities that may reduce the burden of those family with disabled children. In addition, it is recommended that parents focus on controlling their emotional and physical stress in order to cope with the requirements of caring for a disabled child. There is no doubt that the parent will experiences stress, limited financial support, lack of time and emotional and physical exhaustion.

As a parent, they should be more knowledgeable, informative and willing to learn in managing disabled children. It is also recommended that parents engage in positive thinking so that they able to manage these constraints. The limitation of this study is that it does not examine any specific disability in a child, as different disabilities presents a unique set of challenges. In addition, the lack of quality data on the total number of children with disabilities will hinder the ability to generalize the results. Future research should aim to investigate strategies to assist parents in managing the challenges they face effectively and practicably. It is also important to note that issues and challenges of caring for children with disabilities do not equally affect the QoL of all caregivers (Ganjiwale et. al., 2016). There would be a number of factors affecting the QoL of caregivers, and it is recommended that future research be undertaken to investigate the differences of QoL between families with disabled children and families without disabled children in Malaysia.

\section{Acknowledgements}

This research was made possible by a LESTARI grant from Universiti Teknologi MARA (Grant no: 600IRMI/DANAKCM5/3/LESTARI (200/2017).

\section{References}

Allik H, Larson J and Hans Smedje. (2006) Health-Related Quality of Life in Parents of School-Age Children with Asperger Syndrome or High Functioning Autism. Health and Quality of Life Outcomes, 4:1 doi: 10.1186/1477-7525-41

Amar H. S. (2008). Meeting the Needs of Children with Disability in Malaysia. Medical Journal of Malaysia; 63(1): 13. https://www.ncbi.nlm.nih.gov/pubmed/18935722

Ashforth, B., Kreiner, G. and Fugate, M. (2000). All in a Day's Work: Boundaries and Micro Role Transitions. Academy of Management Review, 25(3), 472-491. Retrieved from http://amr.aom.org/content/25/3/472.short DOI: $10.2307 / 259305$

Brehaut, J. C., Kohen, D. E., Garner, R. E., Miller, A. R., Lach, L. M., \& Klassen, A. F. (2009). Health among Caregivers of Children with Health Problems: Findings from a Canadian Population-Based Study. American Journal of Public Health. 99(7), 1254-1262. DOI: 10.2105/AJPH.2007.129817

Button, S., Pianta, R. C., \& Marvin, R. S. (2001). Partner support and maternal stress in families raising young children with cerebral palsy. Journal of Developmental and physical disabilities, 13(1), 61-81. https://link.springer.com/article/10.1023/A:1026509400487

Cramm, J. M., \& Nieboer, A. P. (2011). Psychological well-being of caregivers of children with intellectual disabilities: Using parental stress as a mediating factor. Journal of Intellectual Disabilities, 15(2), 101-113. https://doi.org/10.1177/1744629511410922

Department of Social Welfare (2015) Statistics of Social Welfare Department. Available at: www.jkm.gov.my Hobfoll, S. E. (1989). Conservation of resources: A new attempt at conceptualizing stress. American psychologist, 44(3), 513. http://dx.doi.org/10.1177/1744629511410922

Hobfoll, S. E. (1991). Traumatic stress: A theory based on rapid loss of resources. Anxiety Research, 4(3), 187-197. https://doi.org/10.1080/08917779108248773

Hobfoll, S. E. (2011). Conservation of resources theory: Its implication for stress, health, and resilience. The Oxford handbook of stress, health, and coping, 127-147. https://psycnet.apa.org/record/2010-25086-007

Ganjiwale, D., Ganjiwale, J., Sharma, B., \& Mishra, B. (2016). Quality of life and coping strategies of caregivers of children with physical and mental disabilities. Journal of family medicine and primary care, 5(2), 343. DOI: $10.4103 / 2249-4863.192360$

Law of Malaysia (2008). Act 685. Persons with Disabilities Act. Percetakan Nasional Malaysia Bhd., Kuala Lumpur 
Juhásová, A. (2015). Comparison of quality of life of families with children with disability and families with children without disability. Procedia Social and Behavioral Sciences, 174, 3378-3384 https://doi.org/10.1016/j.sbspro.2015.01.1007

Joyner, J., \& Valerie Leake (2018, January 24). A Brief Review of the Conservation of Resources Theory as it Applies to Military Trauma. Retrieved from http://traumapsychnews.com/2018/01/a-brief-review-of-the-conservation-ofresources-theory-as-it-applies-to-military-trauma/

Kamaralzaman, S., Ying, T. C., Mohamed, S., Toran, H., Satari, N., \& Abdullah, N. (2018). The economic burden of families of children with cerebral palsy in Malaysia. Malaysian Journal of Public Health Medicine, 2018(Specialissue1), 156-165.

Kruithof, N., Haagsma J.A., Karabatzakis, M., Cnossen, M.C., de Munter, L, van de Ree, C.L.P., de Jongh, M.A.C. \& Polinder, S. (2018). Validation and reliability of the Abbreviated World Health Organization Quality of Life Instrument (WHOQOL-BREF) in the hospitalized trauma population. International Journal of the Car of the Injured. 49(10), 17961804. DOI: 10.1016/j.injury.2018.08.016

Loprest, P., \& Davidoff, A. (2004). How children with special health care needs affect the employment decisions of low-income parents. Maternal and Child Health Journal, 8(3), 171-182. DOI:10.1023/B:MACI.0000037650.83572.81

Muhamad N.A.N. \& Alfa N.A.E.E. (2016) Special education for children with disabilities in Malaysia: Progress and obstacles. Malaysian Journal of Society and Space. 12(10) $78-87$.

Meyers, M. K., Brady, H. E., \& Seto, E. Y. (2000). Expensive children in poor families: The intersection of childhood disabilities and welfare. Public Policy Institute of Calif.

Nagaraju, K., \& Wilson, J. (2013). Burden and stress perceived by mothers having autistic children. International Journal of Multidisciplinary Research in Social \& Management Sciences, 1(4), 53-57.

Newacheck P.W. \& McManus M. (1998). Financing health care for disabled children. Paediatrics 1998;81: 385-94.

Norshidah M.S. \& Manisah M.A. (2010) Students with Visual Impairments and Additional Disabilities. Procedia Social and Behavioral Sciences. 7(C) 714-719 DOI: http://dx.doi.org/10.17977/um005v1i12017p060

Olsson, M. B., \& Hwang, C. P. (2001). Depression in mothers and fathers of children with intellectual disability. Journal of intellectual disability research, 45(6), 535-543. https://doi.org/10.1046/j.1365-2788.2001.00372.x

Pushpalatha. R. \& Shivakumara. K., (2016). Stress, Burden and Coping between Caregivers of Cerebral Palsy and Autism Children. The International Journal of Indian Psychology. 4(1), 80.

Shirley A.S., Amily F., Zulhabri I., Norashikin H. (2017). Work-Family Conflict among Working Parents of Children with Autism in Malaysia, Procedía Computer $\quad$ Science. $105 \quad$ (2017) $345 \quad-\quad 352$. https://doi.org/10.1016/j.procs.2017.01.232

Siti Nor Ismalina I.B , Ismarulyusda I., Azriani A.R., Nur Zakiah M.S., Normah C.D., Syarif H.L., Muhammad Faiz M.I. (2016). Health and quality of life among the caregivers of children with disabilities: A review of literature. Asian Journal of Psychiatry. 23 (2016) 71-77. https://doi.org/10.1016/j.ajp.2016.07.007

Sy, S. Z., \& Ms, L. (2011). Assessing the unmet needs among caregivers of children with disabilities at the communitybased rehabilitation centres in Selangor. Malaysian Journal of Public Health Medicine, 11(2), 32-40. https://doi.org/10.1111/hsc.12325

Tan, K. L., \& Yadav, H. (2008). Assessing the development of children with disability in Malaysia. The Medical journal of Malaysia, 63(3), 199-202. https://www.ncbi.nlm.nih.gov/pubmed/19248689

UNICEF (2016). Childhood Disability in Malaysia: A study of Knowledge, Attitudes and Practices. Retrieved from www.unicef.org/Malaysia.

UNICEF, (2017). Childhood Disability in Malaysia. A study of Knowledge, Attitudes and Practices. Retrieved from: https://www.unicef.org/malaysia.

11, S. E. (2011). Conservation of resources theory: Its implication for stress, health, and resilience. In S. Folkman (Ed.), The Oxford handbook of stress, health, and coping (127-147). DOI: 10.1080/1047840X.2015.1002377

Hobfoll, S. E. (2011). Conservation of resources theory: Its implication for stress, health, and resilience. The Oxford handbook of stress, health, and coping, 127-147. https://psycnet.apa.org/record/2010-25086-007

New York: Oxford University Press Vasilopoulou E., \& Nisbet J. (2016). The quality of life of parents of children with autism spectrum disorder: A systematic review. Research in Autism Spectrum Disorders 23, 36-49. DOI: 10.1016/j.rasd.2015.11.008 